Case Report

\title{
Penile Fracture, Surgical Success and Complication Rate in 26 Cases
}

\author{
Naser Alfgi", Saliem Abuaniza, Abdulghany Hussien \\ Tripoli Medical Center, Urology Department, Tripoli, Libya \\ Email address: \\ Nasr1997@yahoo.com (N. Alfgi) \\ ${ }^{*}$ Corresponding author
}

\section{To cite this article:}

Naser Alfgi, Saliem Abuaniza, Abdulghany Hussien. Penile Fracture, Surgical Success and Complication Rate in 26 Cases. International Journal of Clinical Urology. Vol. 3, No. 2, 2019, pp. 36-39. doi: 10.11648/j.ijcu.20190302.12

Received: September 19, 2019; Accepted: September 29, 2019; Published: October 20, 2019

\begin{abstract}
A fracture of the penis is defined as the rupture of the tunica albuginea of corpora cavernosa as a result of blunt trauma to the erect penis commonly occurring during sexual intercourse or masturbation. Our objective is to present our experience in the management of penile fracture, surgical success and the complication rate. This study took place in the Urology Department of the Tripoli Medical Center on 26 patients in the form of a retrospective study between August 2003 and July 2018. The ages of the patients were between 19 and 61 years old (mean 34.23 years). The diagnosis was based on history and clinical examination. A circumferential sub coronal incision was made followed by degloving the penis to its base. The hematoma was evacuated and the tear was repaired using absorbable, interrupted stitches and the skin was closed with $3 / 0$ undyed vicryl. Cefotriaxon $1 \mathrm{gm}$ IV was given pre-operatively and continued for 5 days post-operative and diazepam $5 \mathrm{mg}$ tab was given twice daily. The cause of penile fracture was masturbation in 11 patients. Intercourse was the cause in 9 cases and 6 were caused by rolling over the erect penis during sleep. All of the patients presented with swelling and ecchymosis and 18 patients underwent surgery within the first $24 \mathrm{hrs}$ while 8 patients were operated on in the 2 nd day. After six months of follow up, 19 patients (73.1\%) were without complaint, of which $17(89.47 \%)$ of them were operated on within the first 24 hrs and 2 patients (10.53\%) were operated on in the 2 nd day. Within the group, 7 patients $(26.9 \%)$ had complications of which 6 patients were operated on after 24 hrs from the time of trauma and one patient who was operated on in the first $24 \mathrm{hrs}$ and complained of painless penile deviation. Three patients had complications with penile deviation and with painful erection while 3 patients had complications of penile deviation. This experience showed that penile fracture is a rare urological emergency. Early surgical correction of penile fractures can be successful in preserving normal erections without significant complications whilst delayed operative management is associated with complications such as penile deviation and painful erection.
\end{abstract}

Keywords: Penile Fracture, Tunica Albuginea, Sub-coronal Incision, Corpus Cavernosu

\section{Introduction}

Penile fracture is a relatively uncommon condition $[1,2]$ and is a rare Urological emergency. [3] The true incidence is unknown. It has been reported as 1 of 175,000 hospital admissions, [3] and in a review of 183 publications, 1331 cases were reported between January 1935 and July 2001, mostly from the Mediterranean region. [4] Fracture of the penis is defined as the rupture of the tunica albuginea of the corpora cavernosa, as a result of blunt trauma to the erect penis commonly occurring during sexual intercourse or masturbation. [1, 5] In the erect state the tunica thins from 2 $\mathrm{mm}$ to $0.25 \mathrm{~mm}$ and is more susceptible to traumatic tearing. Urethral injury with penile fracture is uncommon. [6] The common causes are trauma to an erect penis during coitus, masturbation and unconscious nocturnal penile manipulations or rolling over in bed. [7, 8] Suggestive clinical features are a popping or cracking sound with significant pain and immediate detumescence, swelling and bruising with a lateral deformity and hematoma are evident on examination. Urethral bleeding indicates an associated urethral injury. [6] Diagnosis is clinical and a "rolling sign", with the palpation of localised 
clot over the tunical tear site which is pathognomic. [7, 10] In doubtful cases cavernosography, penile ultrasonography and even MRI have been used. [7, 11] Treatment remains controversial but immediate surgical exploration and repair is widely accepted as the therapy of choice in penile fracture and is superior to conservative treatment. $[1,8,12]$

\section{Patients and Methods}

This study was carried out in the Urology Department of the Tripoli Medical Center as a retrospective study between August 2003 and July 2010. In total, 26 patients with penile fracture were included. The ages of the patients age varied between 19 and 61 years old (mean 34.23 years). The patient characteristics and details of the clinical picture were recorded by taking a detailed history including age, marital status, the activity leading to the injury, progress of symptoms until arriving at the hospital. The findings of the physical examination such as hematoma, deformity, swelling and discolouration were noted. The diagnosis was clinical and investigation such as cavernosography was not done. Baseline investigations such as haemoglobin, random blood sugar, urinalysis and E.C.G were done for all patients as a requirement for general anaesthesia. A standard operative technique was adopted in all patients. The patients were catheterised. An artificial erection was attained by injecting normal saline. A circumferential sub coronal incision was made followed by degloving the penis to its base. The hematoma was evacuated and the tunical tear identified. The tear was repaired with absorbable (vicryl) interrupted stitches and the skin was closed with $4 / 0$ undyed vicryl. The drain was not kept. A pressure dressing was applied and antibiotics were given to all patients pre-operatively and continued for 5 days post-operative. An injection of cefotriaxon $1 \mathrm{gm} \mathrm{IV}$ and diazepam $5 \mathrm{mg}$ tab twice daily were routinely used. Finally the length of the hospital stay, post-operative complications, progress of patients and follow up were also recorded.

\section{Result}

The patient's mean age was 34.23 years (range: 19-61 years). 17 patients were single and 9 were married.

Table 1. Patient age.

\begin{tabular}{lll}
\hline Age & Cases & \% \\
\hline 19 to 24 & 3 & 11.53 \\
25 to 30 & 9 & 34.61 \\
31 to 36 & 7 & 26.92 \\
37 to 42 & 5 & 19.23 \\
43 to 48 & 1 & 3.84 \\
$>49$ & 1 & 3.84 \\
\hline
\end{tabular}

Table 2. Marital state.

\begin{tabular}{lll}
\hline Marital state & Cases & \% \\
\hline Single & 17 & 65.38 \\
Married & 9 & 34.62 \\
\hline
\end{tabular}

The cause of penile fracture in these patients was masturbation in 11 patients, intercourse was the cause in 9 cases, and 6 were caused by rolling over the erect penis during sleep.

Table 3. Mechanism of fracture.

\begin{tabular}{lll}
\hline Mechanism of fracture & Cases & \% \\
\hline Vaginal intercourse & 9 & 34.61 \\
Masturbation & 11 & 42.30 \\
Rolling over in bed during sleep & 6 & 23.07 \\
& 26 & 100 \\
\hline
\end{tabular}

All of the patients presented with swelling and ecchymosis, while 24 patients presented with pain, and 21 patients presented with penile angulations.

Table 4. Clinical presentation.

\begin{tabular}{lll}
\hline Clinical feature & Cases & \% \\
\hline Swelling & 26 & 100 \\
Ecchymosis & 26 & 100 \\
Pain & 24 & 92.3 \\
Penile angulation & 21 & 92.3 \\
Urethral bleeding & 0 & 0 \\
Voiding difficulty & 0 & 0 \\
\hline
\end{tabular}

In total, 21 patients presented directly to the Tripoli Medical Center Emergency and only 5 patients were referred from other hospitals.

Table 5. Mode of patient presentation.

\begin{tabular}{lll}
\hline Type of presentation & Cases & \% \\
\hline TMC Emergency & 21 & 80.76 \\
Referred & 5 & 19.2 \\
\hline
\end{tabular}

The diagnosis of penile fracture for all patients depends only on clinical history and examination. In total, 18 patients underwent surgery within the first $24 \mathrm{hrs}, 6$ patients were operated on in the 2nd day. Only one patient was operated on in 3rd day and one patient on the 4th day. The record shows 2 of 6 patients presented within the first $24 \mathrm{hrs}$ but operated on in the 2 nd day that were due to hesitation on the part of the patients to sign the surgical consent. The other 4 patients were due to delay in presentation but the surgical interference was done on the day of presentation.

Table 6. Time of surgery for time of injury.

\begin{tabular}{lll}
\hline Time of surgery after time of trauma & Cases & $\%$ \\
\hline$<24 \mathrm{hr}$ & 18 & 69.23 \\
$>24 \mathrm{hr}<48 \mathrm{hr}$ & 6 & 23.07 \\
48 to $72 \mathrm{hr}$ & 1 & 3.84 \\
$>72 \mathrm{hr}$ & 1 & 3.84 \\
\hline
\end{tabular}

The injury was detected at the right cavernous in 9 cases (34.61\%), on the left side in 13 cases $(50 \%)$, at the base of the penis in 3 cases $(11.53 \%)$, and the dorsal vein injury in only one case $(3.84 \%)$.

Table 7. Site of injury.

\begin{tabular}{lll}
\hline Site of lesion & Cases & \% \\
\hline Right cavernous & 9 & 34.61 \\
Left cavernosum & 13 & 50 \\
Base & 3 & 11.53 \\
Dorsal vein only & 1 & 3.84 \\
\hline
\end{tabular}


The duration of the catheterisation ranged from 3 to 4 days, and the range of the hospital stay from 5 to 9 days, giving a mean length of hospital stay at 6.44 days. Two patients were lost to follow-up, and considered as patients without complaint after 6 months. Other patients were seen within 4 weeks after discharge and the following up after 3 months and 6 months.

After 6 months of follow up, 19 (73.1\%) of the patients were without complaint, $17(89.47 \%)$ of them were operated on within the first $24 \mathrm{hrs}$ from the time of injury. A total of 2
$(10.53 \%)$ patients were operated on in the 2nd day, $6(23.08 \%)$ patients had complications and all of them were operated on after $24 \mathrm{hrs}$ from the time of trauma except for one patient (3.84\%) who was operated on within the first $24 \mathrm{hrs}$ and complained of painless penile deviation. Three patients had a complication with penile deviation and one with painful erection.

Two patients were operated on in the 3rd day and the 4th day as they suffered complications of penile deviation, painful erection and impotence respectively.

Table 8. Time of surgery for trauma and complication after 6 months.

\begin{tabular}{|c|c|c|c|c|c|c|c|c|c|c|c|}
\hline \multirow{2}{*}{$\begin{array}{l}\text { Time of } \\
\text { Surgery }\end{array}$} & \multirow{2}{*}{ cases } & \multicolumn{2}{|c|}{ Complaint } & \multicolumn{2}{|c|}{ Penile deviation } & \multicolumn{2}{|c|}{ Painful erection } & \multicolumn{2}{|c|}{ impotence } & \multicolumn{2}{|c|}{ Missed follow-up } \\
\hline & & cases & $\%$ & cases & $\%$ & cases & $\%$ & cases & $\%$ & cases & $\%$ \\
\hline$<24 \mathrm{hr}$ & 18 & 17 & 94.44 & 1 & 5.55 & 0 & 0 & 0 & 0 & 2 & 11.11 \\
\hline$>24 \mathrm{hr}$ to $<48$ & 6 & 2 & 33.33 & 3 & 50 & 1 & 16.66 & 0 & & 0 & \\
\hline $48 \mathrm{hr}$ to $<72 \mathrm{hr}$ & 1 & 0 & 0 & 1 & 100 & 1 & 100 & 0 & & 0 & \\
\hline$>72 \mathrm{hr}$ & 1 & 0 & 0 & 0 & 0 & 0 & 0 & 1 & 100 & 0 & \\
\hline & 26 & 19 & 73.07 & 5 & 19.23 & 2 & 7.69 & 1 & 3.84 & 2 & 7.69 \\
\hline
\end{tabular}

\section{Discussion}

This experience has shown that penile fracture is a rare urological emergency. Most of the cases occurred during sexual activity. Usually the penis slips out of the vagina and then is thrust against the perineum or symphysis pubis, which results in a tear of the tunica albuginea. Some of the cases $(9 / 26)$ occurred during sexual intercourse. Other cases reported that most injuries occurred because of forcible and manual deflection of the erect penis (11/26). Although the diagnosis of the case is easy, treatment has some controversy. Presently, no long-term prospective randomised studies are available to establish whether operative or conservative management is the optimal treatment. However, many support the necessity for immediate surgery $[2,7,8,9,10]$. Delayed operative management is associated with a $75 \%$ complication rate (angulation, impotence and painful markedly deformed erection). However there were no significant complications during intercourse in 17 cases managed by surgical repair within the first 24 hours from the time of trauma and 2 cases were operated on in the 2nd day from the time of injury. Across the literature, the overall average hospital stay was 14 days in patients treated conservatively and 6.44 days for the patients in this study managed with operations. It would seem that immediate surgery is necessary to prevent the formation of the fibrous tissue that causes penile curvature in order to achieve good results and to shorten the hospital stay. Late or postponed surgery achieved less favourable results due to fibrous tissue formation, and the incision of deeper intracavernous fibrotic tissue [7]. Preoperative cavernosography has been recommended by some of the authors to demonstrate the site of injury and plan the surgical approach $[11,12]$. In this study the medical practitioners were able to clinically identify the site of the injury preoperatively in all of the patients. Therefore none of our patients underwent cavernosography and neither was it necessary to perform retrograde urethrography.
Urethral injuries associated with penile fracture were reported as frequently as $22 \%$. However the authors did not meet any demonstrable urethral injury during history taking or clinical examination or during operations. The surgical approach was by a subcoronal circumferential [2, 13]. The circumferential subcoronal was performed and the penis degloved to obtain sufficient area for repair of the tunica albuginea and any associated conditions (dorsal vein ruptures). Similar to the reports of other authors, there were no significant complications precluding sexual intercourse in the patients in this study.

\section{Conclusion}

It was concluded that most cases of penile fracture can be diagnosed on the basis of clinical findings and immediate surgical correction of such penile fractures can be successful in preserving normal erections without significant complications, requires only a short hospital stay and there is rapid return of sexual function. Delayed operative management is associated with complications such as penile deviation and painful erection.

\section{References}

[1] Xu MX, Zhou Z, Yao HJ, Zhang K, Da J, Zhang M, Wang Z, Lu MJ. Comparison of different approaches to the surgical treatment of penile fractures: quicker return to sexual function with longitudinal incisions. International journal of impotence research. 2016 Jul; 28 (4): 155.

[2] Shakya P, Choudhary B, Tripathi K, Sawai M. Penile fracture rare urological emergency. International Surgery Journal. 2016 Dec 13; 3 (1): 420-1.

[3] Amer T, Wilson R, Chlosta P, AlBuheissi S, Qazi H, Fraser M, Aboumarzouk OM. Penile fracture: a meta-analysis. Urologia internationalis. 2016; 96 (3): 315-29.

[4] Yalom ID. Psicoterapia esistenziale. Neri Pozza Editore; 2018 Dec 28. 
[5] Barros R, Schul A, Ornellas P, Koifman L, Favorito LA. Impact of Surgical Treatment of Penile Fracture on Sexual Function. Urology. 2019 Apr 1; 126: 128-33.

[6] Girgin R. Complete Urethral Rupture Related with Penile Fracture Occurring during Sexual Intercourse: A Case Report and Review of the Literature/Cinsel Iliski Nedeniyle Olusmus Penil Fraktur ile Iliskili Tam Uretral Ruptur: Olgu Sunumu ve Literatur Taramasi. Journal of Urological Surgery. 2018 Jun 1; 5 (2): 112-6.

[7] Dell'Atti L. The role of ultrasonography in the diagnosis and management of penile trauma. Journal of ultrasound. 2016 Sep 1; 19 (3): 161-6.

[8] Persaud S, Persaud M, Naraynsingh V. Fracture of the Penis: A Review. UROLOGY. 2019 Apr.

[9] Kumar L, Tiwari R, Arya MC, Sandhu A, Vasudeo V, Baid M. A tertiary center experience of fracture penis: Early surgical management with a clinical diagnosis. Urological Science. 2018 Nov 1; 29 (6): 298.
[10] Blair BM, Vilson F, Kocher NJ, Kloniecke E, Clark JY. Longitudinal Rupture of Distal Corpus Cavernosum With Concomitant Urethral Injury: An Uncommon Result of a Common Mechanism. Urology. 2018 Aug 1; 118: e5-6.

[11] Wespes E, Libert M, Simon J, Schulman CC. Fracture of the penis: conservative versus surgical treatment. Eur Urol. 2008, 13: 166-168.

[12] Seaman EK, Santarosa RP, Walton GR. Immediate repair: key to managing the fractured penis. Contemp Urol. 2005; 5: 13.

[13] Vahidi S, Karami H, Maleki H. Penile fracture with bilateral corporeal tears and complete disruption of the urethra following anal intercourse: a case report and review of literature. Journal of Case Reports. 2018; 6 (4): 42-4. 